Sãdhanā, Vol. 18, Part 6, December 1993, pp. 963-983. (C) Printed in India.

\title{
Temperature and torque determination in brake drums
}

\author{
V T V S RAMACHANDRA RAO ${ }^{1}$, L S RAJARAM ${ }^{1}$ and \\ K N SEETHARAMU ${ }^{2}$ \\ ${ }^{1}$ Advanced Engineering Department, Brakes India Ltd., Madras 600050, \\ India \\ ${ }^{2}$ Department of Mechanical Engineering, Indian Institute of Technology, \\ Madras 600036, India
}

MS received 12 December 1991; revised 23 October 1992

\begin{abstract}
Simulation of temperature distribution in a brake drum and determination of drum brake torque has been carried out using finite element methods. The simulated temperature distribution and the brake torque determined were compared with observations carried out using an inertia dynamometer with a data-logging system. There is good agreement between the predicted temperature distribution and the brake torque determined with the test results on the dynamometer.
\end{abstract}

Keywords. Temperature determination; torque determination; brake drums; simulated temperature distribution.

\section{Introduction}

Improved multilane motor ways allow increased speeds of automobiles with special demand on fuel efficiency, cost reduction through material savings, body comfort and vehicle stability in high-speed vehicle.

This means a reduction in unsprung mass and lowering the centre of gravity of the vehicle. Thus, the need arises for designing comparatively smaller and lightweight brakes. Increased traffic density in towns requires, however, that brakes absorb more energy per unit time and at more frequent intervals.

Thus modern brakes have to be lighter and cope with increase in energy absorption while their sizes need to be smaller.

Brake drums constitute a major weight in brake assemblies. Thus, for design optimization for reducing drum weights and for checking the brake performance variations during frequent applications, analysis for drum temperature with time is needed. While applying the brake, the major share of the thermal energy (about 95\%) is dissipated through the drum while the rest of it goes into the brake shoe. This thermal energy diffuses through conduction within the brake drum and dissipates by convection and radiation from the outer surfaces of the brake drum. Temperatures within the drum are time-dependent and hence difficult to measure through conventional methods. Hence, fast-response data logging equipment is required. The 
time and effort required to conduct experimental work on different drum designs are prohibitively high.

Thermal failure of brakes is not due to excessive temperatures alone but due to a combination of high temperatures and high stresses. Thus importance of assessing the peak temperatures and the stresses through the high temperature gradients has been well recognised (Fazekas 1953).

Analytical methods have been used considering the drum as an infinitely long parallel slab and the heat as a moving source for theoretical prediction of temperature rise/pressure distributions. Experimental validation of transient temperatures and pressure distributions has been attempted (Newcomb 1958-59a). Literature survey indicates that analytical investigations and experimental verification are done only for $0.1 \mathrm{~g}$ deceleration level fade cycles with $2.0 \mathrm{~min}$ cycle time. The theory has not been verified at higher deceleration levels (normally specified by the standards) and the drum has been considered only as a ring.

Conventional analyses assume rigid drums and shoes and also implicitly assume a sinusoidal pressure distribution (Newcomb 1963). These analyses give theoretical predictions which are not consistent with observations. The thermal and physical distortions and rigidities of mating pairs are the major causes for deviation between theory and observation. Distortions cause loss of contact area at the interface and this leads to temperature 'flashes' (Fazekas 1953). The need for analysis of temperature rise and pressure distribution becomes vital as speeds of automobiles increase. Fins on drums/ventilation on discs are incorporated along with more conformable linings to obviate these problems.

Numerical techniques such as finite difference methods and finite element methods have been used to develop numerical models for parametric studies (Newcomb 1958-59a; Sisson 1978; Ramachandra Rao \& Subramani 1993). These attempts have brought about a good understanding of the design of the product. The precise assessment of the energy input, more realistic heat-transfer coefficients and a knowledge of material property variations are needed to obtain a better prediction of the temperatures and the stresses. In view of the smaller size of the wheels and larger dissipation of the energy in brake systems, it is essential to know the peak temperatures attained during repeated cycles to make sure of positive braking action.

The present paper deals with the prediction of temperature distribution in brake drums during fade and recovery cycles and determination of brake torque in typical commercial vehicle brakes.

\section{Analysis}

For the analysis, the drum brake and the lined shoe are considered. The heat generation due to brake action is assumed to be both in the lining as well as in the drum of $0.0001 \mathrm{~m}$ thickness on either side of the interface.

The temperature variation in the circumferential direction is neglected (Newcomb 1958-59a) at the speeds the drum rotates. Thus the variation of temperature $T$ with time is given by the equation

$$
\frac{1}{r} \cdot \frac{\partial}{\partial r}\left(k_{r} \cdot r \cdot \frac{\partial T}{\partial r}\right)+\frac{\partial}{\partial z}\left(k_{z} \frac{\partial T}{\partial z}\right)+G=\rho C \frac{\partial T}{\partial t} .
$$


The boundary conditions for this partial differential equation are the expressions for the heat transfer between the outer drum surface and the atmosphere through the convection and radiation modes. The heat transfer to the brake shoe is of the order of $5 \%$ of the total heat generated (Newcomb 1958-59b; Ashworth et al 1977; Ramachandra Rao et al 1985) and hence, to reduce the size of the problem, the shoe portion is neglected.

The forced convection heat transfer from the outer drum occurs due to the velocity induced by the moving automobile. Therefore the heat transfer from the outer drum surface to the atmosphere is given by

$$
Q=h A_{0}\left(T_{1}-T_{x}\right)
$$

The brake drum is divided into eight noded isoparametric elements with quadratic shape function $N_{i}$ associated with each node $i$. The unknown temperature is approximated in the solution domain, at any time, by

$$
T=\sum_{i=1}^{n} N_{l} T_{l}(t)
$$

where $T_{l}$ is the time-dependent temperature at node $i$.

Substituting (3) in (1) and applying Galerkin's method, we obtain the equation

$$
[C]\{T\}+[K]\{T\}=\{F\}
$$

in which typical matrix elements are

$$
\begin{aligned}
K_{i j} & =\sum_{e} \int_{v}\left(k_{r} \frac{\partial N_{1}}{\partial r} \frac{\partial N_{j}}{\partial r}+k_{z} \frac{\partial N_{i}}{\partial z} \frac{\partial N_{j}}{\partial z}\right) \mathrm{d} V+\sum_{e} \int_{s} h N_{i} N_{j} \mathrm{~d} s \\
C_{i j} & =\sum_{e} \int_{v} N_{i} h N_{j} \mathrm{~d} v \\
F_{l} & =\sum_{e} \int_{s} N_{i} h T \mathrm{~d} s+\int_{v} G N_{i} \mathrm{~d} v
\end{aligned}
$$

where the summations are carried out over each element and $K_{r}, K_{z}$ are functions of temperature. Since the properties like $K_{r}, K_{z}$ etc. are variables, an enthalpy formulation (which is capable of accounting for the phase change, if it exists) is used,

$$
H=\int \rho c \mathrm{~d} T .
$$

The details of this technique are available in Comini et al (1974) and Morgan et al (1981). For solving the differential equation (4), a three-level time stepping scheme, DUPONT II is used (Ramachandra Rao 1988). Smail time steps are taken to avoid iteration at each time step. Effect of radiation at the boundary to the ambient is also accounted for

$$
q=\sigma \varepsilon A_{0}\left(T_{1}^{4}-T_{\infty}^{4}\right)
$$

Figure 1 shows the axle layout of the rear axle of a $12,180 \mathrm{~kg}$ GVW (gross vehicle 


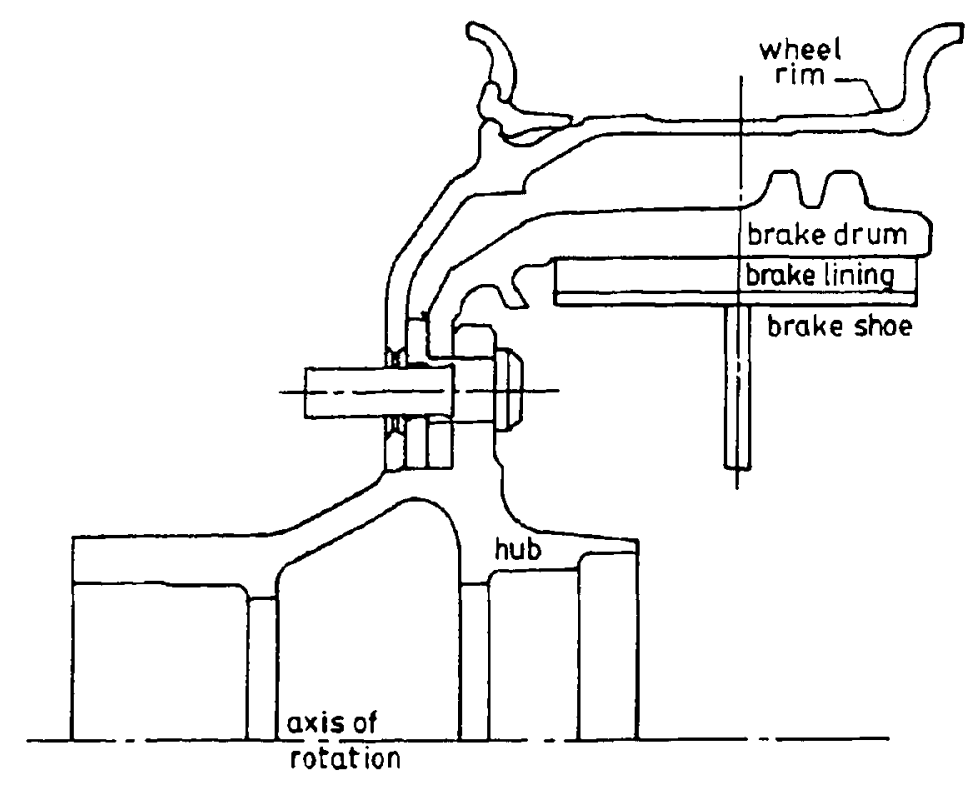

Figure 1. Axle layout of drum brake installation.

weight) commercial truck. This brake has a two-leading shoe brake identified as H2LS brake of size $393.7 \times 152.4 \mathrm{~mm}$ with a lining arc of $100^{\circ}$ on each shoe. For the analysis, an initial velocity of $50 \mathrm{kmph}$ before braking under a deceleration of $0.5 \mathrm{~g}$ conditions are used. This brake drum is designed to absorb $30.4 \%$ of the total energy of the vehicle. Thus the braking ratio $B R$ of this brake is 0.304 . Experiments on an actual brake/drum assembly have been carried out to get the average heat transfer coefficient $h$ as suggested by Highley (1971).

In view of the large variation of thermal conductivity and enthalpy of the drum material with temperature, it is essential that this variation is considered. Every fade cycle is of $1.0 \mathrm{~min}$ duration and consists of $2.84 \mathrm{~s}$ of heating/burnishing followed by $57.16 \mathrm{~s}$ of cooling (brake-off) conditions. Analysis also includes the study of the influence of the fins on drum temperature.

\section{Clock mechanism}

A clock mechanism has been developed (Ramachandra Rao 1988) to take into account heating and cooling in each revolution. Heat is generated for the time interval during which the drum moves from one end of the lined shoe with its varying velocity (say from point 1 to point 2 in figure 2). At this point heat is switched off and cooling through convection and radiation mode is provided for the period the drum moves between the trailing edge of the above shoe and the leading edge of the other shoe (from point 2 to point 3 in figure 2).

As soon as this time elapses, the appropriate thermal energy is given again after taking into account the fact that the drum speed is falling at the rate of $0.5 \mathrm{~g}$ level for the duration the drum passes the second shoe (from point 3 to point 4 in figure 2). Thus the drum is alternatively heated and cooled till it comes to a stop at $2.84 \mathrm{~s}$. Thereafter the drum is cooled for the next $57 \cdot 16 \mathrm{~s}$ at the end of which the next fade cycle commences. Thus heating and cooling during each rotation is taken into account. 


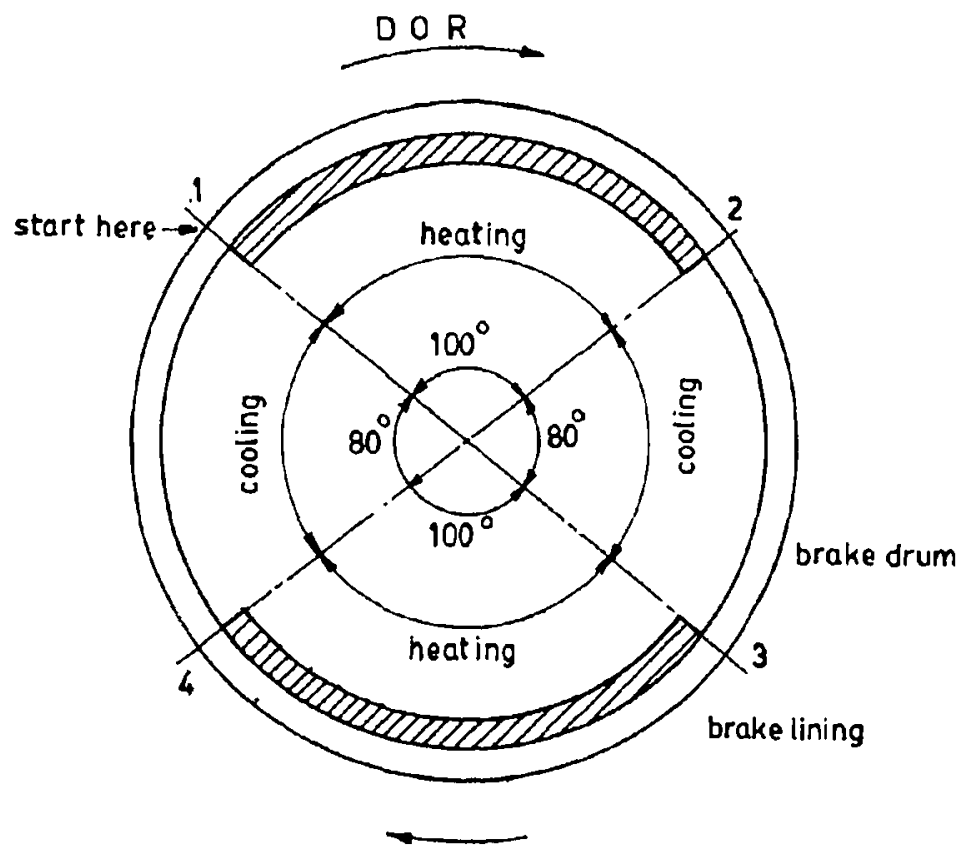

Figure 2. Clock mechanism.

\subsection{Heat inputs}

During braking the kinetic energy is converted into thermal energy. The kinetic energy thus converted in time $\mathrm{d} t$ is given by

$$
\text { (1/2) } M\left(U_{i}^{2}-U_{f}^{2}\right) \text {. }
$$

Heat generation at the interface of the drum and the lining is given by

$$
\dot{q}=N_{c}\left(U_{i}^{2}-U_{f}^{2}\right) t .
$$

This formula takes into account the fact that $95 \%$ of the heat input goes into the brake drum and $5 \%$ enters into the assembly lined shoe.

\subsection{Cooling at the inside surface}

The heat dissipation from the inner surface when it is not under the influence of the brake is taken as negative heat input,

$$
\dot{q}=-h A_{i}\left(T_{b}-T_{\infty}\right) / V_{i} .
$$

Table 1 gives the heat input during brake on and off conditions inside the drum (figure 2).

\section{Loss of contact area}

The diameter of the brake is invariably made smaller than the diameter of the drum (say at least by $0.0002 \mathrm{~m}$ ), for ease of assembly. Thus the crowning effect is always noticed in the new brake assemblies before bedding. Bedding brings up the contact 
Table 1. Time/energy inputs for drum brake analysis in clock mechanism (assuming 100\% contact area).

\begin{tabular}{|c|c|c|c|c|c|}
\hline \multirow[b]{2}{*}{ Revolution } & \multicolumn{2}{|c|}{ Rotation } & \multicolumn{2}{|c|}{ Energy inputs $\left(\mathrm{MJ} / \mathrm{m}^{3} \mathrm{~s}\right)$} & \multirow{2}{*}{$\begin{array}{l}\text { Time lapsed from } \\
\text { start (second) }\end{array}$} \\
\hline & From & To & Heating & Cooling & \\
\hline I & $\begin{array}{l}1 \\
2 \\
3 \\
4\end{array}$ & $\begin{array}{l}2 \\
3 \\
4 \\
1\end{array}$ & $\begin{array}{c}+20823 \\
-\overline{19991} \\
-\end{array}$ & $\begin{array}{c}-\overline{50 \cdot 645} \\
-\overline{59 \cdot 727}\end{array}$ & $\begin{array}{l}0.06299 \\
0.11440 \\
0.18001 \\
0.23365\end{array}$ \\
\hline II & $\begin{array}{l}1 \\
2 \\
3 \\
4\end{array}$ & $\begin{array}{l}2 \\
3 \\
4 \\
1\end{array}$ & $\begin{array}{c}+19123 \\
- \\
+18213 \\
-\end{array}$ & $\begin{array}{c}-\overline{65 \cdot 712} \\
-\overline{70 \cdot 275}\end{array}$ & $\begin{array}{l}0.30224 \\
0.35884 \\
0.43045 \\
0.48960\end{array}$ \\
\hline III & $\begin{array}{l}1 \\
2 \\
3 \\
4\end{array}$ & $\begin{array}{l}2 \\
3 \\
4 \\
1\end{array}$ & $\begin{array}{c}+17255 \\
\overline{16241} \\
-\end{array}$ & $\begin{array}{c}-\overline{73 \cdot 665} \\
-\overline{76 \cdot 302}\end{array}$ & $\begin{array}{l}0.56561 \\
0.62824 \\
0.70900 \\
0.77580\end{array}$ \\
\hline IV & $\begin{array}{l}1 \\
2 \\
3 \\
4\end{array}$ & $\begin{array}{l}2 \\
3 \\
4 \\
1\end{array}$ & $\begin{array}{c}+15159 \\
- \\
+13993 \\
-\end{array}$ & $\begin{array}{c}-\overline{78.269} \\
-\overline{-} \\
-79.525\end{array}$ & $\begin{array}{l}0.86232 \\
0.93425 \\
1.02798 \\
1.10644\end{array}$ \\
\hline V & $\begin{array}{l}1 \\
2 \\
3 \\
4\end{array}$ & $\begin{array}{l}2 \\
3 \\
4 \\
1\end{array}$ & $\begin{array}{c}+12720 \\
+\overline{11306} \\
-\end{array}$ & $\begin{array}{c}-\overline{80.696} \\
-\overline{81.031}\end{array}$ & $\begin{array}{l}1.20995 \\
1.29673 \\
1.41274 \\
1.51239\end{array}$ \\
\hline VI & $\begin{array}{l}1 \\
2 \\
3 \\
4\end{array}$ & $\begin{array}{l}2 \\
3 \\
4 \\
1\end{array}$ & $\begin{array}{c}+9685 \\
+ \\
+7726 \\
-\end{array}$ & $\begin{array}{c}-\overline{80 \cdot 613} \\
-\overline{79 \cdot 106}\end{array}$ & $\begin{array}{l}1.64782 \\
1.76750 \\
1.93725 \\
2.09770\end{array}$ \\
\hline VII & $\begin{array}{l}1 \\
2 \\
3\end{array}$ & $\begin{array}{c}2 \\
3 \\
\text { stop }\end{array}$ & $\begin{array}{c}+5022.6 \\
+\overline{927.9}\end{array}$ & $-\overline{75 \cdot 297}$ & $\begin{array}{l}2 \cdot 35883 \\
2 \cdot 75160 \\
2 \cdot 84381\end{array}$ \\
\hline
\end{tabular}

area close to perfect contact at cold conditions and at 0.2 to $0.3 \mathrm{~g}$ level conditions of braking.

In addition to the above, the thermal expansion phenomenon increases the drum diameter, whereas the variation in the brake shoe diameter is negligibly small compared to that of the drum. Hence, a smaller circle (brake shoe) comes in contact with a bigger circle (brake drum) creating a crowning effect of the shoe on to the drum and thus contact area is decreased. On account of the load there is a certain amount of shoe deflection which increases the contact area. There is however a reduction in the effective contact area.

In figure 3 the actual cross-section of the drum used in the FEM model is shown. The drum is discretized into eight noded isoparametric elements as shown. The total number of nodes are 188 and the total number of elements 47 . The drum thickness (say between nodes 182 and 188 ) is $0.020 \mathrm{~m}$. The distance between node 182 and 184 is $0.0001 \mathrm{~m}$.

The drum is subjected to heating when it is opposite to the brake shoe and to cooling when it is between the shoes. The drum cools down by convection and radiation 


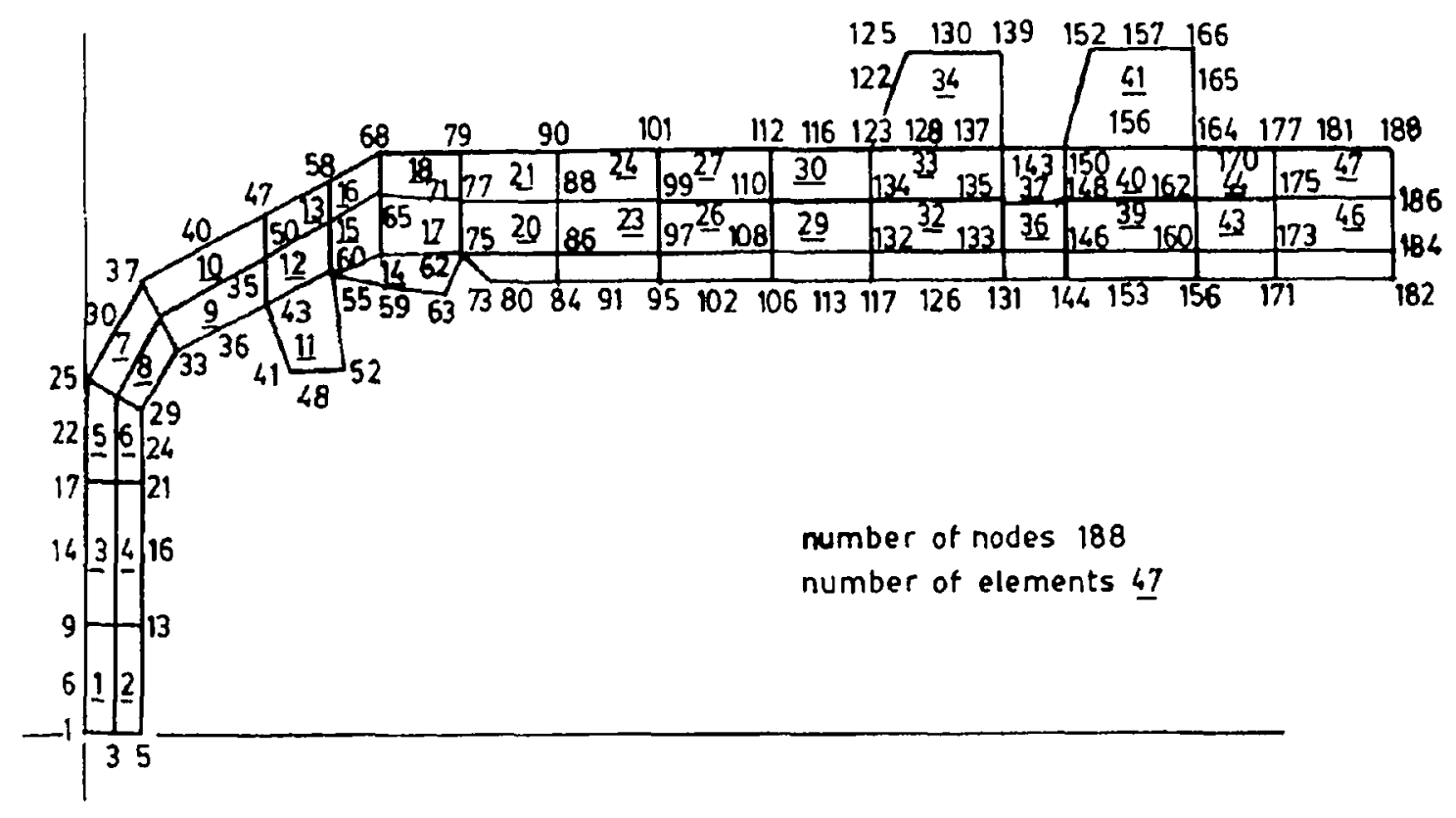

Figure 3. Mesh taken for analysis.

at the top layers, while the inner faces cool only when the cross-section is opposite to the non-lining zones shown (figure 2, arc 2-3 and arc 4-1). The analysis and experiments were carried out for 5 fade cycles.

\section{Experimental investigation}

In order to verify the analysis, an experiment to determine the temperature distribution in the drum has been carried out. Double-ended microprocessor-controlled inertia dynamometers capable of measuring drum temperature through embedded thermocouples and through slip rings have been used. The experiment was carried out by mounting the brake drum assembly on this type of dynamometer, with the capacity of testing commercial brakes fitted on 13 ton/axle rating. The fade cycles were conducted at $50 \mathrm{kmph}$ as per the standards.

The test was conducted in the auto mode where the cycle time is $60 \mathrm{~s}$. It was started by rotating the drum at $260 \mathrm{rpm}$, keeping the initial temperature at $373 \mathrm{~K}$. The brake was applied to achieve a torque equivalent to $0.5 \mathrm{~g}$ deceleration level. The temperature, pressure and the torque were recorded. When the drum came to a stop, it was again rotated at $260 \mathrm{rpm}$ till the cycle time was over. The next brake application was made as explained above and further cycles were continued. Since the test mode was in auto and the application mode was in constant torque, the brake torque and the cycle time was automatically maintained by the micro-processor and the servo controller.

\section{Results and discussion}

The results obtained both by the analysis and experiments are presented in figures 4 to 13. For comparison, both the analysis and the experimental results are plotted on the same graph. 


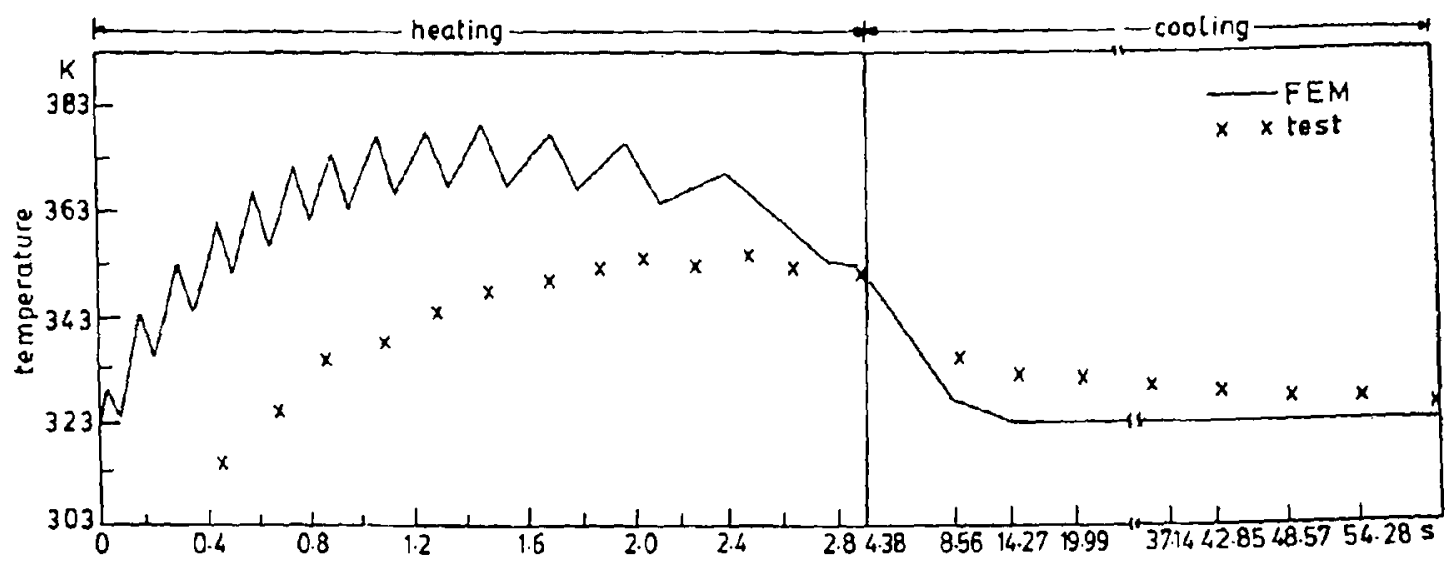

Figure 4. Temperature rise during the first fade cycle.

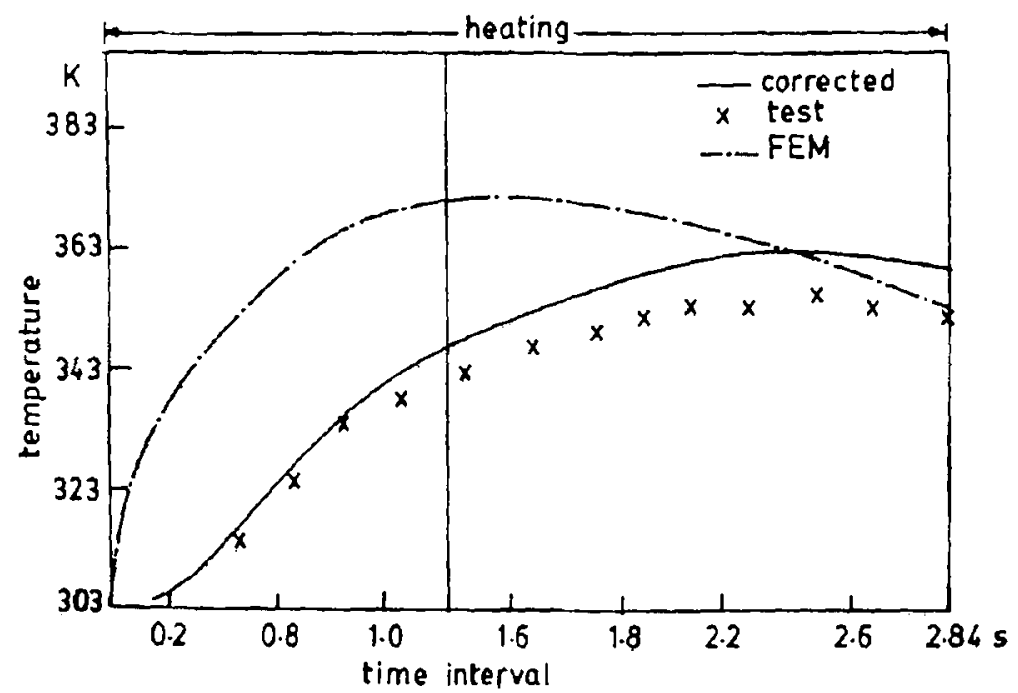

Figure 5. Temperature rise during the first fade cycle (with thermocouple response incorporated).

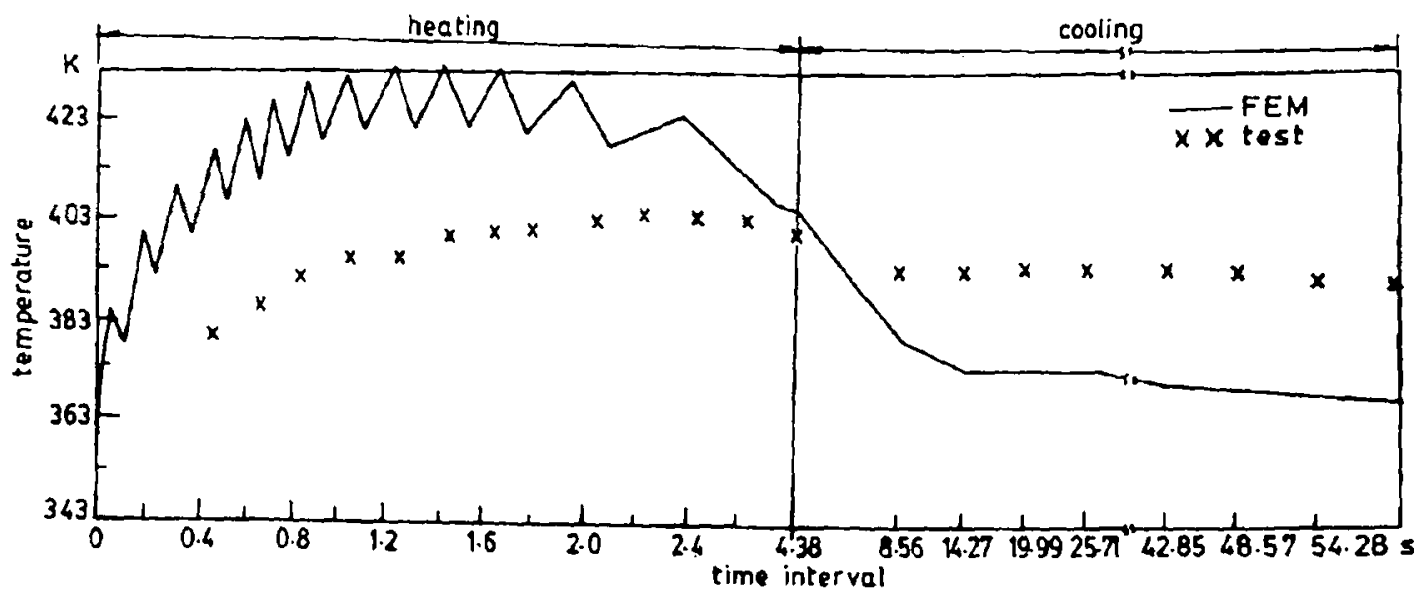

Figure 6. Temperature rise during the fifth fade cycle. 


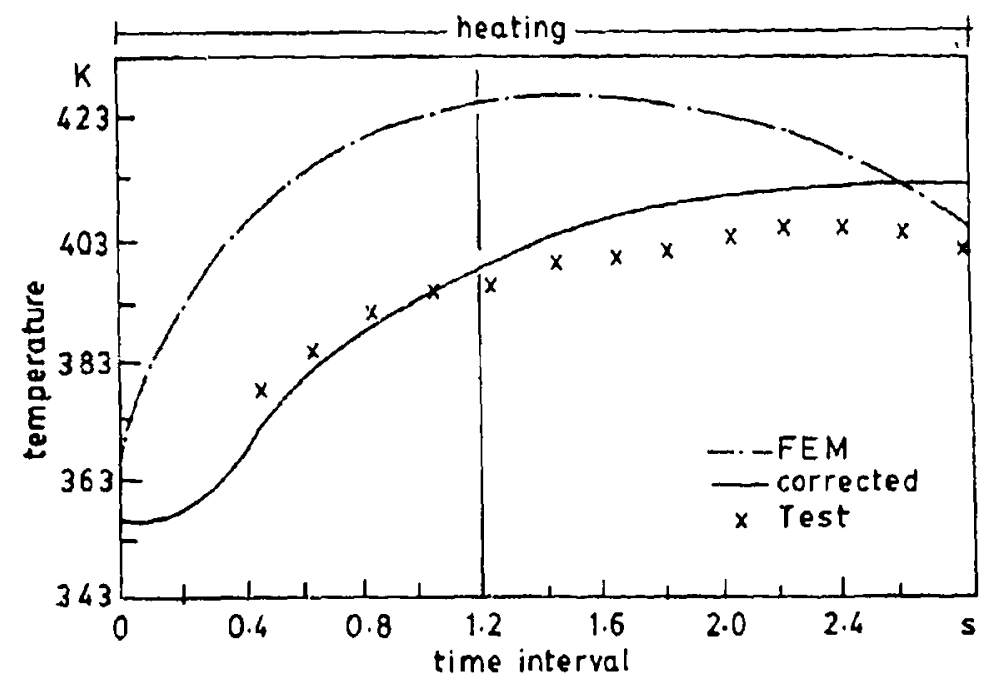

Figure 7. Temperature rise during the fifth fade cycle (with thermocouple response incorporated).

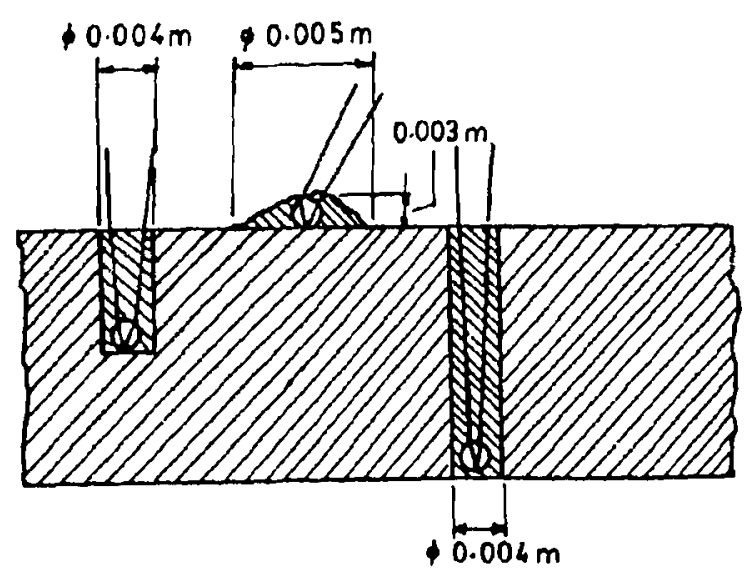

QZa brake orum thermocouple sealing

Dthermocouple bead (approx $0.002 \mathrm{~m}$ sphere)
Figure 8. Schematic diagram of thermocouple installation.

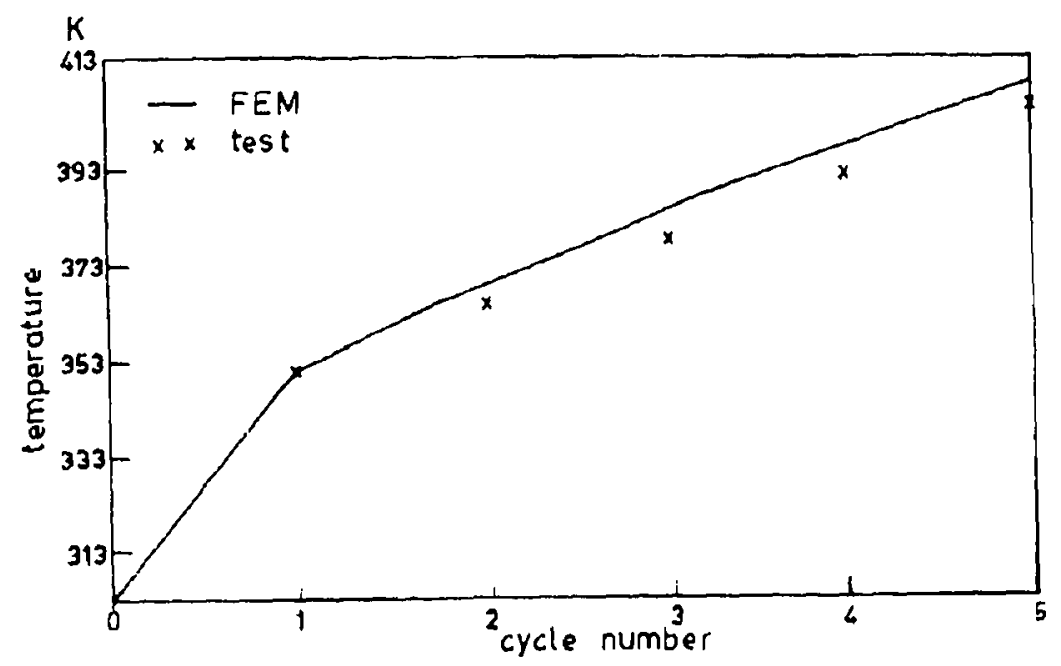

Figure 9. Temperature at the rubbing path at the end of each brake application. 


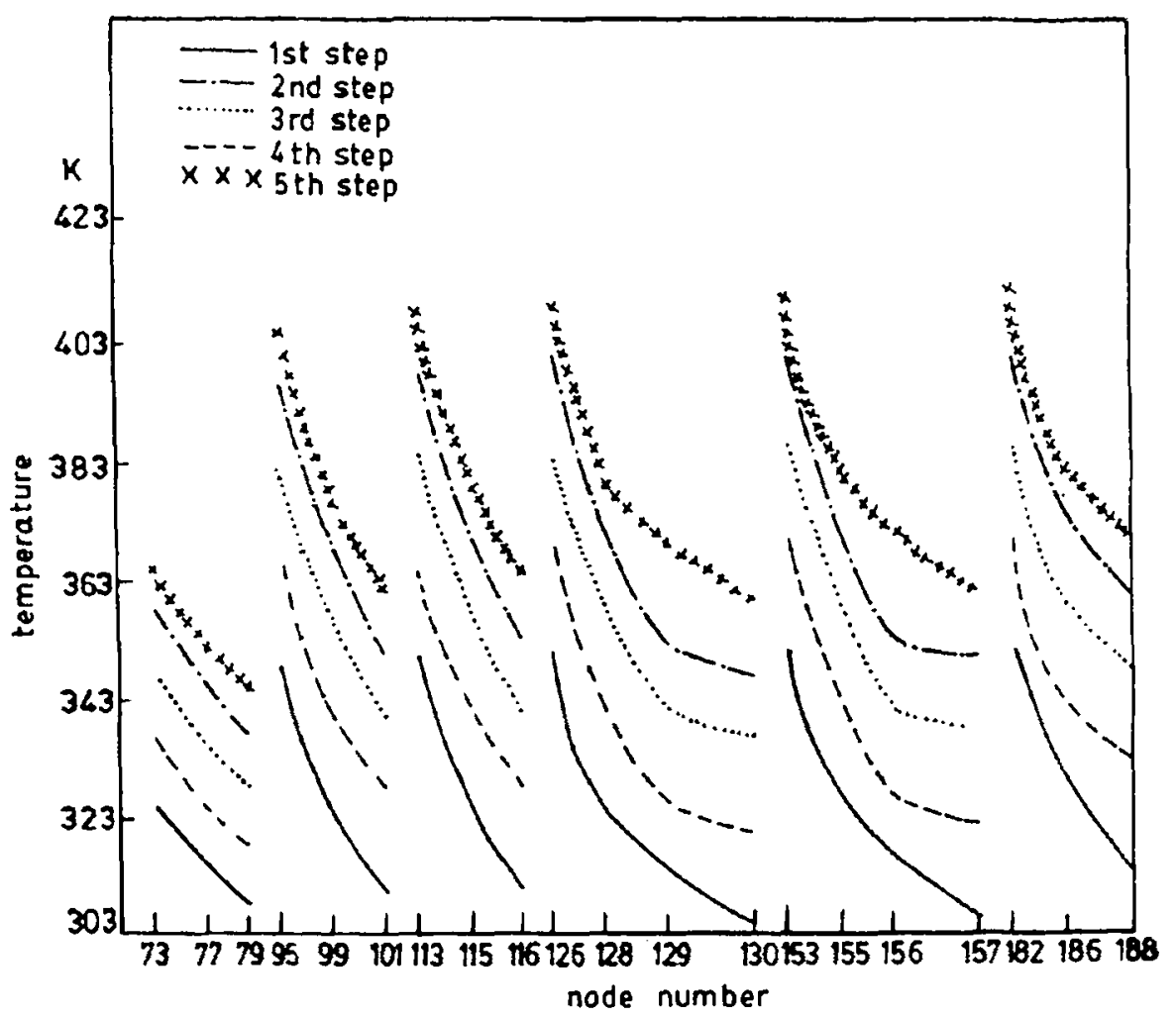

Figure 10. Radial temperature distribution.

Figure 4 shows the temperature rise in the drum (typically for a node 113) both during braking and subsequent cooling during the first fade cycle. As explained earlier, each brake shoe covers 100 degree arc for heating, leaving two 80 degree arcs for cooling in each revolution while the brake is on. This heating and cooling during

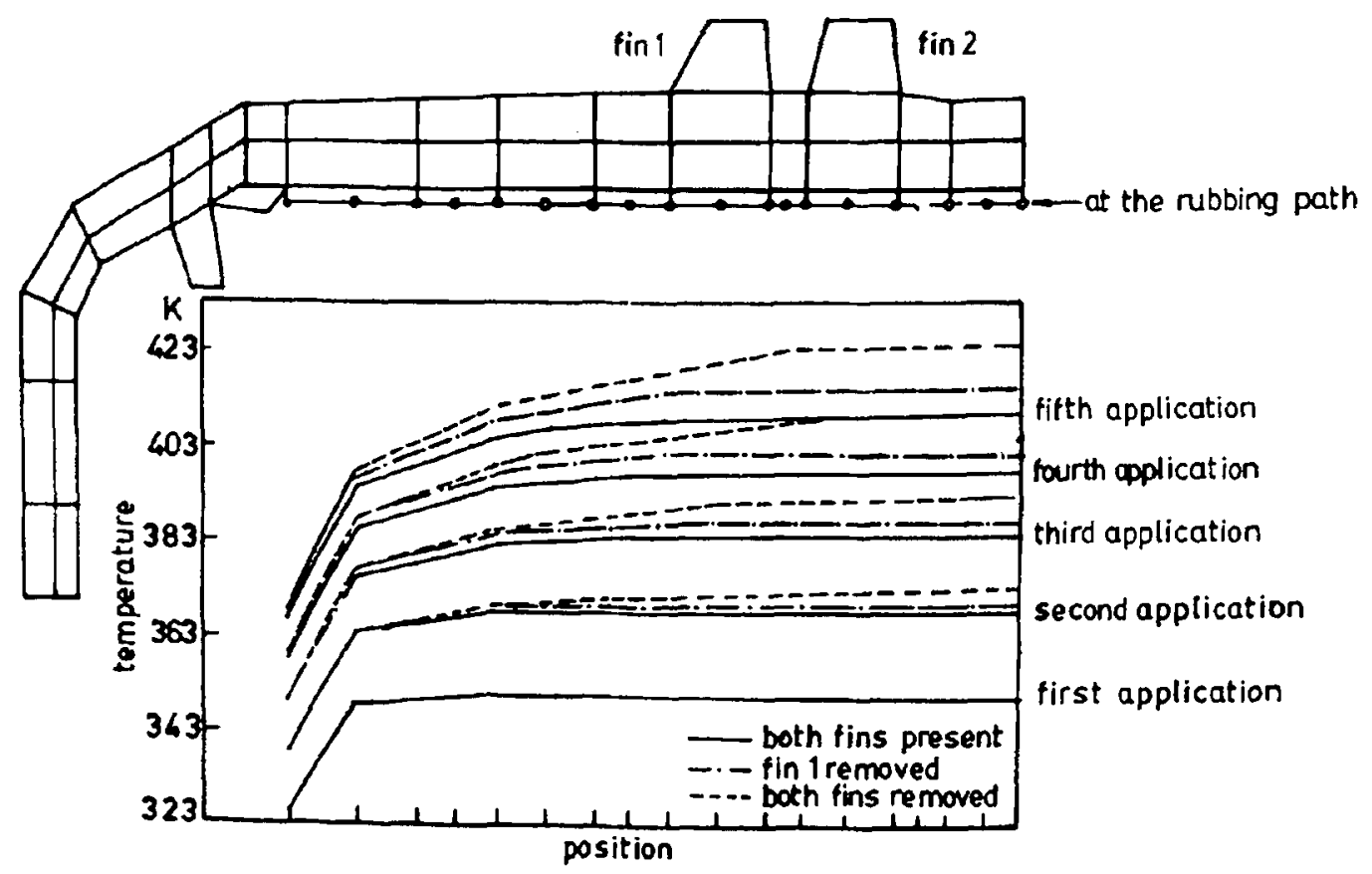

Figure 11. Role of fins on the temperature field - temperatures at the rubbing path. 


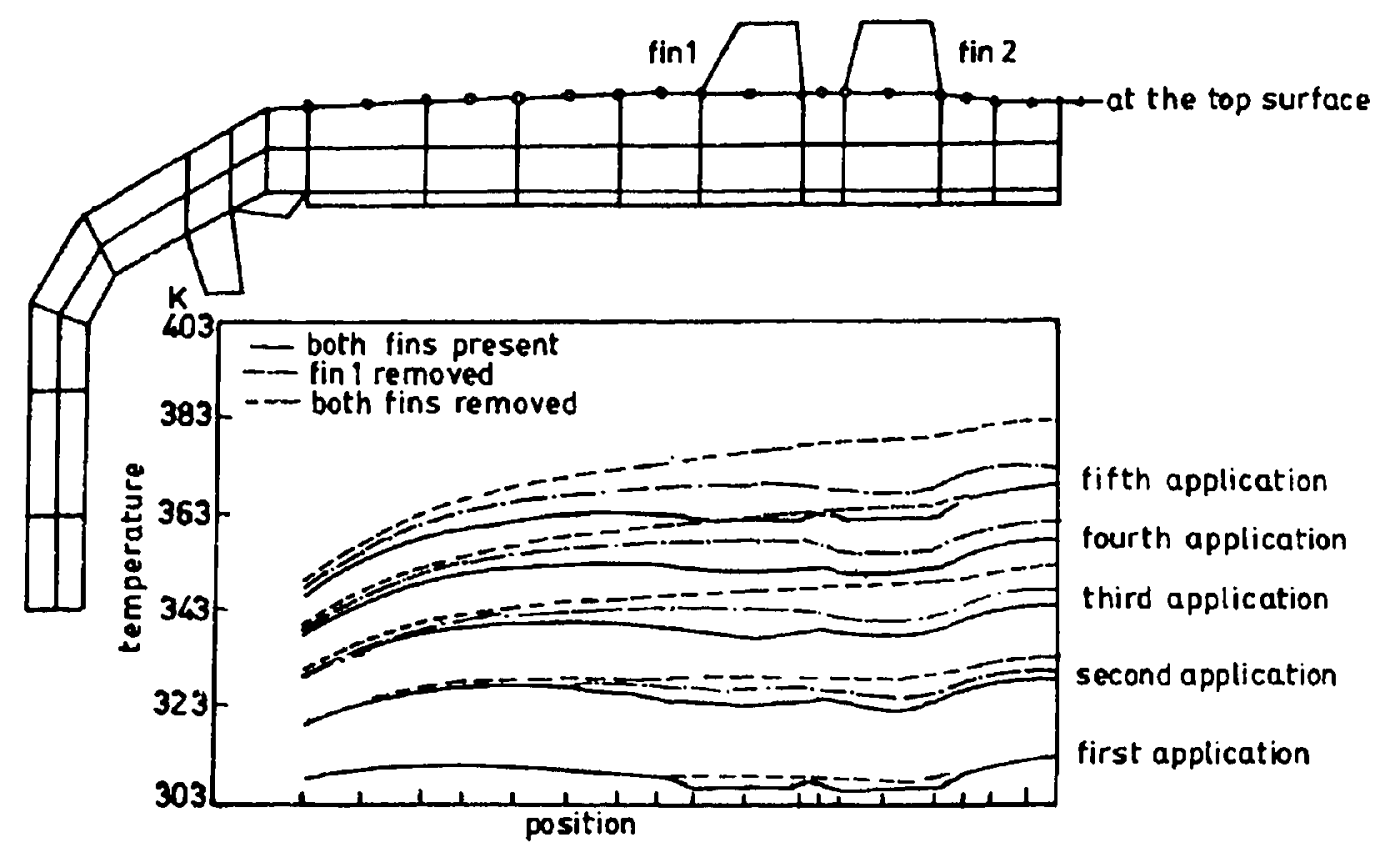

Figure 12. Role of fins on the temperature field - temperatures at the top surface.

the braking period is clearly demonstrated in the curve shown in figure 4 . This process continues till the brake drum comes to a stop. The temperature at the end of the braking period coincides with the experimental value. However, temperature during the braking deviates from the experimental value for reasons explained as follows.

The thermocouple could not be located exactly on the surface of the interface and is located radically away from this rubbing surface, which is allowed in the international standard for thermocouple location. Thus the thermocouple output will always be

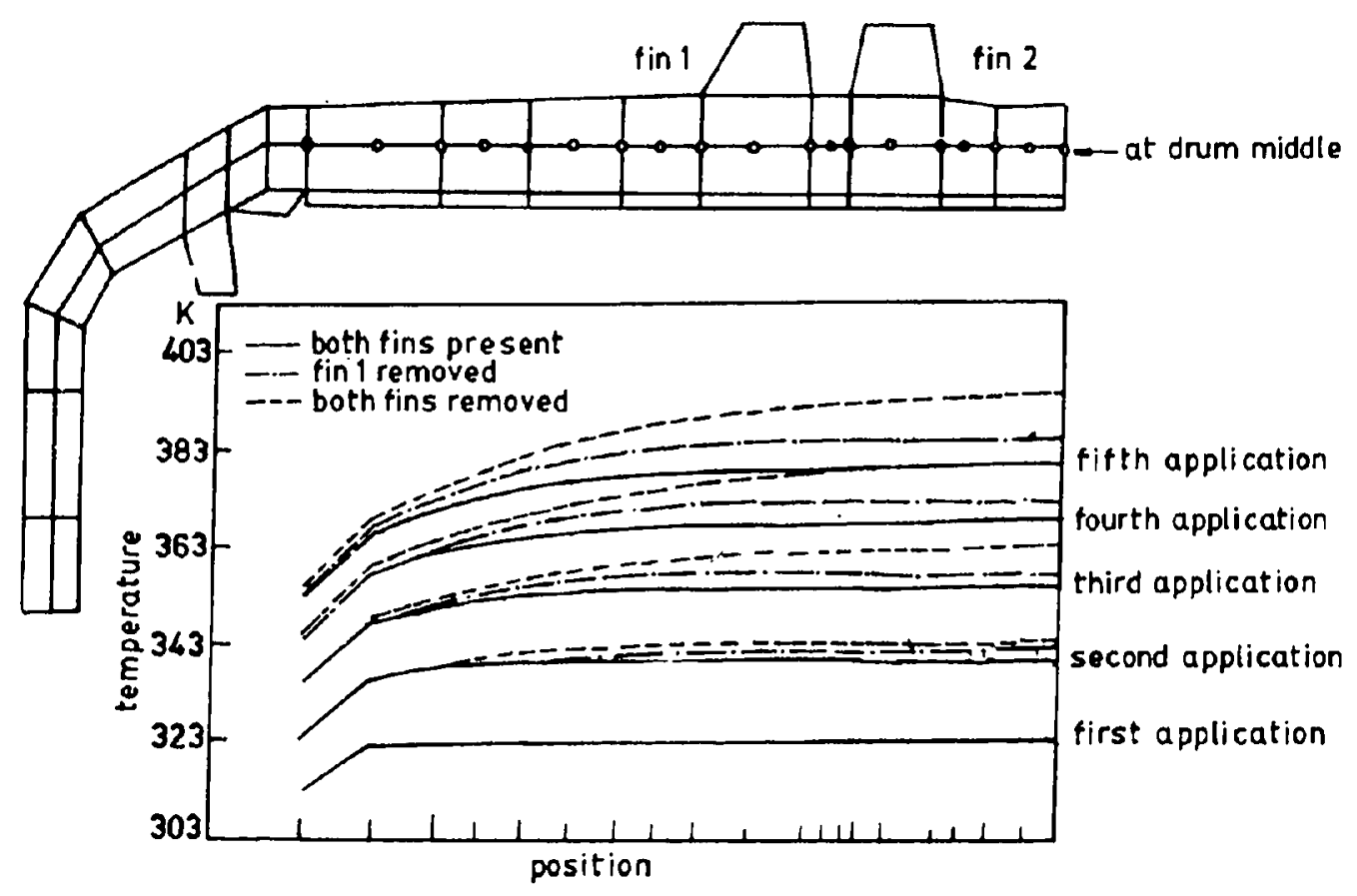

Figure 13. Role of fins on the temperature field - temperatures at the middle of the drum. 
less than it is at the interface. The actual temperature $T$, at the thermocouple location corresponding to the surface temperature $T_{x}(t)$ is obtained by the solution of the governing differential equation,

$$
(\mathrm{d} T / \mathrm{d} t)+T /\left(R_{e} \rho C V\right)=T_{\alpha}(t) /\left(C \rho V R_{e}\right)
$$

where $R_{e}$ is the equivalent resistance. The response is shown in figure 5 for the first fade cycle and in figure 7 for the fifth cycle. It can be observed from these two figures that the difference between the measured temperature and the theoretical response temperature is small. The surface temperature variations $T(t)$ are also shown in these figures. The time constant is given by $0.82(=1 / 1.213)$ which is expected in view of the size of the thermocouple used.

\section{Determination of brake torque}

\subsection{Analysis}

The finite element method was used for the analysis. For this analysis, the effect of variation of pressure along the width of the brake lining is considered, but the drum "bell mouthing" (which is the radially outward deflection of the brake drum at the free edge, as compared to the inner edge, due to the application of braking forces) has not been considered.

Although three-dimensional modelling would be desirable, it is computationally very expensive. Hence, two-dimensional isoparametric elements have been used for modelling the brake shoe, web and thin plate elements of the rim. The brake lining has been replaced by elastic boundary elements which are placed normal to the rim. The stiffness of the boundary elements have been calculated based on the geometry and the mechanical properties of the brake lining.

The analysis was carried out using commercially available SAP IV package for finite element analysis. The analysis yields the normal reactions as the output of the boundary elements. This initial analysis can be considered as a case of static analysis i.e. the forces acting on the brake shoe due to the input force in the static condition. In the second iteration, the tangential drag forces (only compressive or positive reaction forces are taken) are obtained as a product of these normal forces and the coefficient of friction. FEM analysis provides a set of new normal loads (again tensile or negative forces have been deleted), which may be different or the same at the nodes. In the third iteration, the tangential or drag forces are obtained as the product of coefficient of friction and normal reactions (obtained as the output of the second iteration). These, along with the same shoe tip effort are used as inputs to obtain new normal compressive reaction forces at the nodes. The iterations are repeated till the computed torque converges within $0.2 \%$ between any two successive iterations. The analysis converges normally within 5 to 6 iterations. The theoretical analysis was carried out on a Brakes India-Girling two-leading shoe brake (H2LS brake) and a mechanical ' $S$ cam brake used on heavy duty commercial vehicles (iigure 14).

In the case of the H2LS brake, both the shoes are identical in geometry as well as with respect to the forces applied. Hence, only one shoe has been considered for the analysis.

In the case of the ' $S$ ' cam brake, both the shoes are identical geometrically but the magnitude and direction of the input forces for the leading and trailing shoes are 


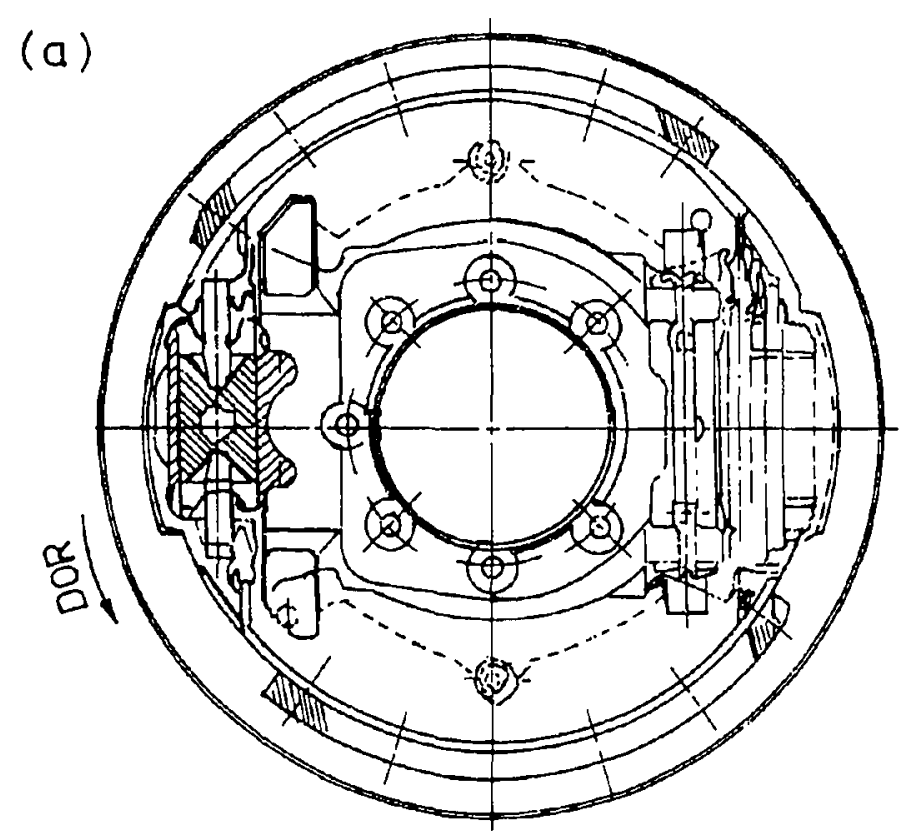

(b)

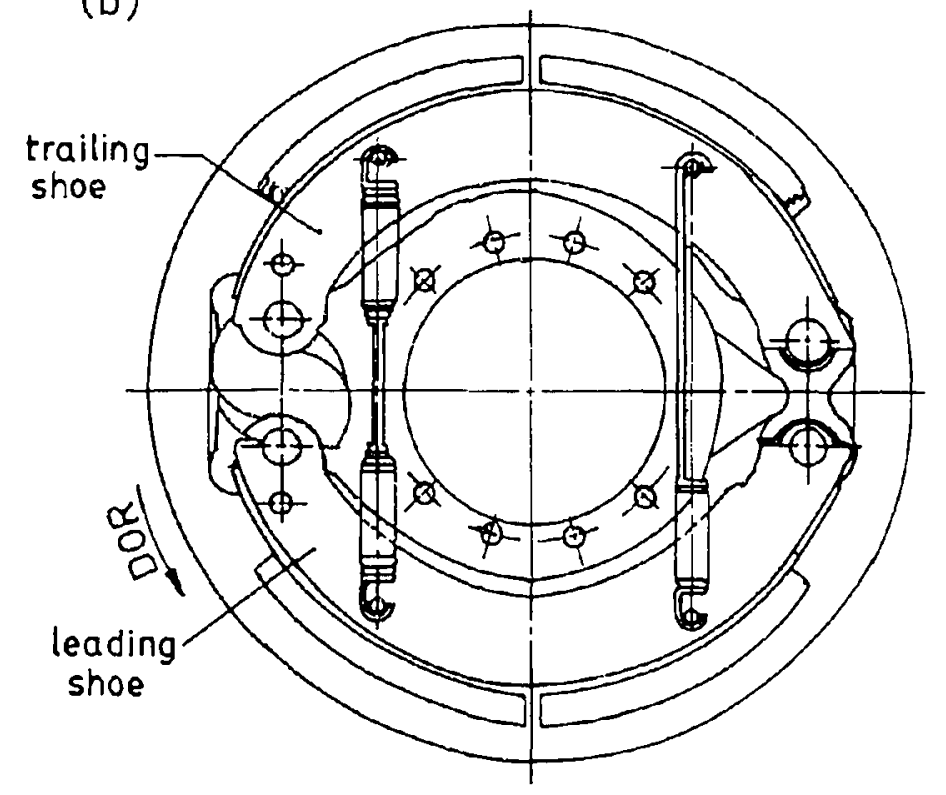

Figure 14. H2LS (a) and ' $S$ ' cam (b) brake assemblies.

different. Hence both the shoes are considered for analysis. In the case of the ' $S$ ' cam brake design, the work done by the leading and trailing shoes will have to be equal. The input forces to the leading and trailing shoes are in the inverse ratio of the respective shoe factors. Hence the analysis for the leading and trailing shoes has been carried out for various input forces for the leading and trailing shoes.

Table 2. Material properties.

\begin{tabular}{|c|c|c|c|}
\hline \multicolumn{2}{|l|}{$\begin{array}{l}\text { Steal (for shoe web } \\
\text { and rim) }\end{array}$} & \multicolumn{2}{|c|}{ Brake lining } \\
\hline Young's modulus & $210,000 \mathrm{MN} / \mathrm{m}^{2}$ & Young's modulus & $300 \mathrm{MN} / \mathrm{m}^{2}$ \\
\hline Poisson's ratio & 0.297 & Poisson's ratio & 0.2 \\
\hline Web thickness & $8 \mathrm{~mm}$ & Lining thickness & $12 \cdot 7 \mathrm{~mm}$ \\
\hline Rim thickness & $4 \mathrm{~mm}$ & & \\
\hline
\end{tabular}



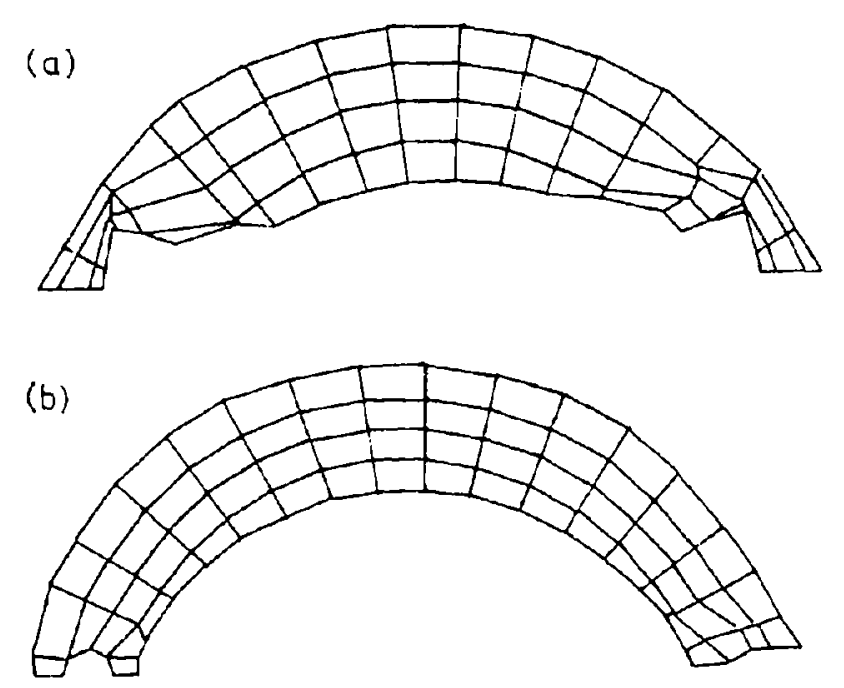

Figure 15. Finite element mesh, (a) H2LS brake shoe and (b) ' $S$ ' cam brake shoe.

The details of the finite element discretization of the brake shoes of the H2LS and ' $S$ ' cam brake are shown in figure 15 . The brake lining segments have been replaced by linear elastic boundary elements whose stiffness corresponds to the actual brake lining. These springs have been placed normal to the shoe rim and are used to obtain the normal reaction forces. The input force to the shoe is applied at the point where the hydraulic piston or the ' $S$ ' cam actuates the brake shoe. The abutment end of the shoe is suitably constrained depending on whether the shoe is sliding or pivoted.

For the same shoe tip effort (design value), the converging torque values are obtained using iteration and FEM analysis for various values of coefficient of friction, for the given configuration of the brake. This gives the coefficient of friction-torque relationship. The particular value of coefficient of friction which corresponds to the desired output torque is called the dynamic coefficient of friction $\left(\mu_{d}\right)$. The corresponding torque and compressive normal reactions decide the pressure distribution. Thus this analysis takes into account the loss of area contact due to distortions and starting from a static problem converts itself into a dynamic problem through an iterative technique and hence provides the converging torque output and the dynamic coefficient of friction. The normal and the tangential forces at the convergence conditions for design torque value are taken for the stress analysis of the components.

The mechanical properties of the brake lining are obtained by compressing a specimen of a brake lining in a Hounsfield Tensometer and obtaining the load deflection curve. From this curve secant modulus and Poisson's ratio have been estimated. The Young's modulus and Poisson's ratio of the steel shoe web and rim have also been determined by carrying out tensile tests with the tensometer. The mechanical properties thus determined are used in the analysis (see table 2).

\subsection{Experimental work}

The torque output and the brake factor of H2LS and $S$-cam brakes are measured in an inertia dynamometer. The inertia dynamometer can simulate the actual working conditions of the brake regarding the dynamic axle weights, drum speeds, air velocities flowing over the drum etc. The input force, output torque, drum temperature, fluid displacements and other related parameters can be measured and recorded. The brake factor i.e., the relationship between input force and output torque is then calculated. 
Standard brake assemblies and drums have been used for carrying out the experimental work. The linings used in these brakes have been in use for many years and as such they have been found to be stable. Initially the linings are burnished to achieve full contact with the drum and care is taken not to subject the lining to temperatures higher than $373 \mathrm{~K}$. The burnishing process achieves full liner contact with the drum and also stabilizes the friction characteristics.

After burnishing, the performance test is carried out at drum speeds corresponding to a vehicle speed of $50 \mathrm{kmph}$ and with drum temperature maintained around $373 \mathrm{~K}$. The performance test is carried out with increasing input forces and the corresponding output corques are measured. These test results are used in conjunction with the corresponding theoretical analysis and the dynamic coefficient of friction $\left(\mu_{d}\right)$ is arrived at.

\section{Results and discussion}

In the case of the H2LS brake shoe, as the input force is easily calculated from the hydraulic pressure, analysis was carried out using this input force for different values of coefficient of friction of lining. The converged torque output and shoe factors for each value of the coefficient of friction of lining were obtained. The variation of shoe factor and torque with coefficient of friction of lining, based on the theoretical analysis for the H2LS brake are shown in figures $16 \& 17$. From the dynamometer performance tests on the H2LS brake with standard lining arc, the torque and brake factor values were measured and these results were compared with the theoretical values to determine the dynamic coefficient of friction for this brake, which was found to be $\mu=0.365$.

The results obtained with coefficient of friction $=0.365$ and experimental work with reduced lining arcs of 100 degrees, 90 degrees and 80 degrees are shown in table 3 .

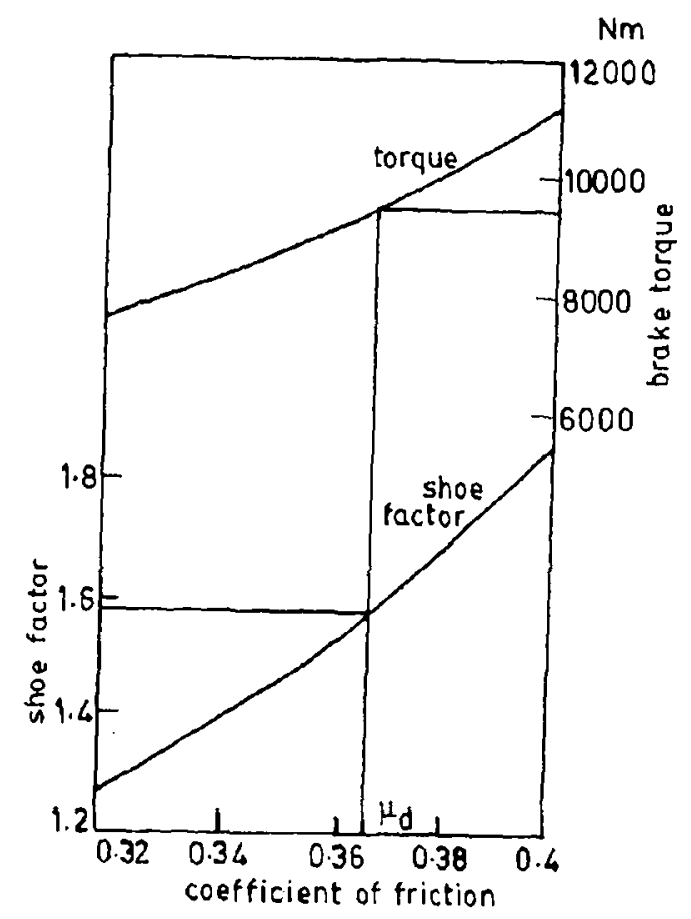

Figure 16. Variation of shoe factors with coefficient of friction H2LS brake shoe. 


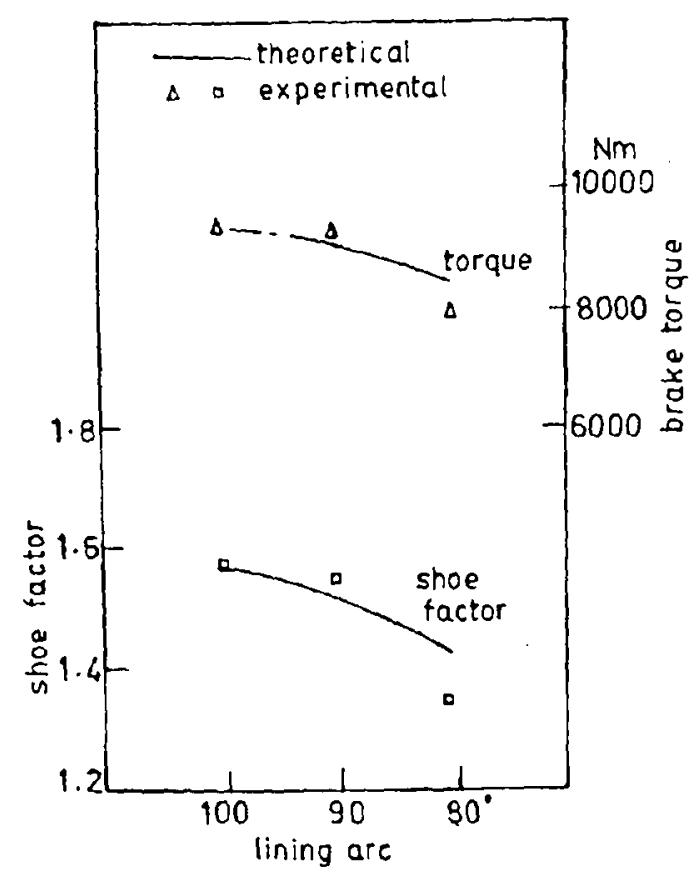

Figure 17. Variation of shoe factors and torque with lining arc $-\mathrm{H} 2 \mathrm{LS}$ brake shoe.

It can be seen that the maximum discrepancy between the theoretical predictions and experimental data is less than $6 \%$ at 80 degrees arc length.

In the case of the ' $S$ ' cam brake, since the exact values of input forces to the leading and trailing shoes are not known, exhaustive theoretical analysis was carried out for various values of input force and coefficient of friction. The results of theoretical analysis of shoe factors and torques with various input forces for the leading and trailing shoes are shown in figure 18.

From the experimental work with standard lining arc the output torque is measured from the performance test and overall brake factor is calculated. As it is known that the output work done by both the leading and the trailing shoes, in the case of the ' $S$ ' cam brake, is the same, the input forces of leading and trailing shoes must be inversely proportional to their respective shoe factors. Based on the above condition and knowing the overall brake factor and output torque (from experimental work) the dynamic coefficient of friction $\left(\mu_{d}\right)$ for the ' $S$ ' cam brake was found to be 0.47 .

Similar to the H2LS brake, the arc lengths were reduced in the case of ' $S$ ' cam brake also. The results of theoretical analysis with reduced lining arcs at the same dynamic coefficient of friction and experimental data with reduced lining arcs are shown in figure 19 and table 4 . The discrepancy between the experimental data and theoretical prediction is less than $6.5 \%$.

Table 3. Torque/brake and brake factor variation with arc length of lining in H2LS brake.

\begin{tabular}{|c|c|c|c|c|c|c|}
\hline & \multicolumn{2}{|c|}{100} & \multicolumn{2}{|c|}{90} & \multicolumn{2}{|c|}{80} \\
\hline & $\begin{array}{l}\text { Theor- } \\
\text { etical }\end{array}$ & $\begin{array}{l}\text { Experi- } \\
\text { mental }\end{array}$ & $\begin{array}{l}\text { Theor- } \\
\text { etical }\end{array}$ & $\begin{array}{l}\text { Experi- } \\
\text { mental }\end{array}$ & $\begin{array}{l}\text { Theor- } \\
\text { etical }\end{array}$ & $\begin{array}{l}\text { Experi- } \\
\text { mental }\end{array}$ \\
\hline $\begin{array}{l}\text { Shoe tip effort }(\mathrm{N}) \\
\text { Torque }(\mathrm{Nm}) \\
\text { Shoe factor }\end{array}$ & $\begin{array}{l}15390 \\
9579 \\
1.58\end{array}$ & $\begin{array}{c}15390 \\
9582 \\
1.58\end{array}$ & $\begin{array}{c}15390 \\
9290 \\
1.53\end{array}$ & $\begin{array}{l}15390 \\
9467 \\
1.56\end{array}$ & $\begin{array}{c}15390 \\
8823 \\
1.46\end{array}$ & $\begin{array}{c}15390 \\
8193 \\
1.35\end{array}$ \\
\hline
\end{tabular}



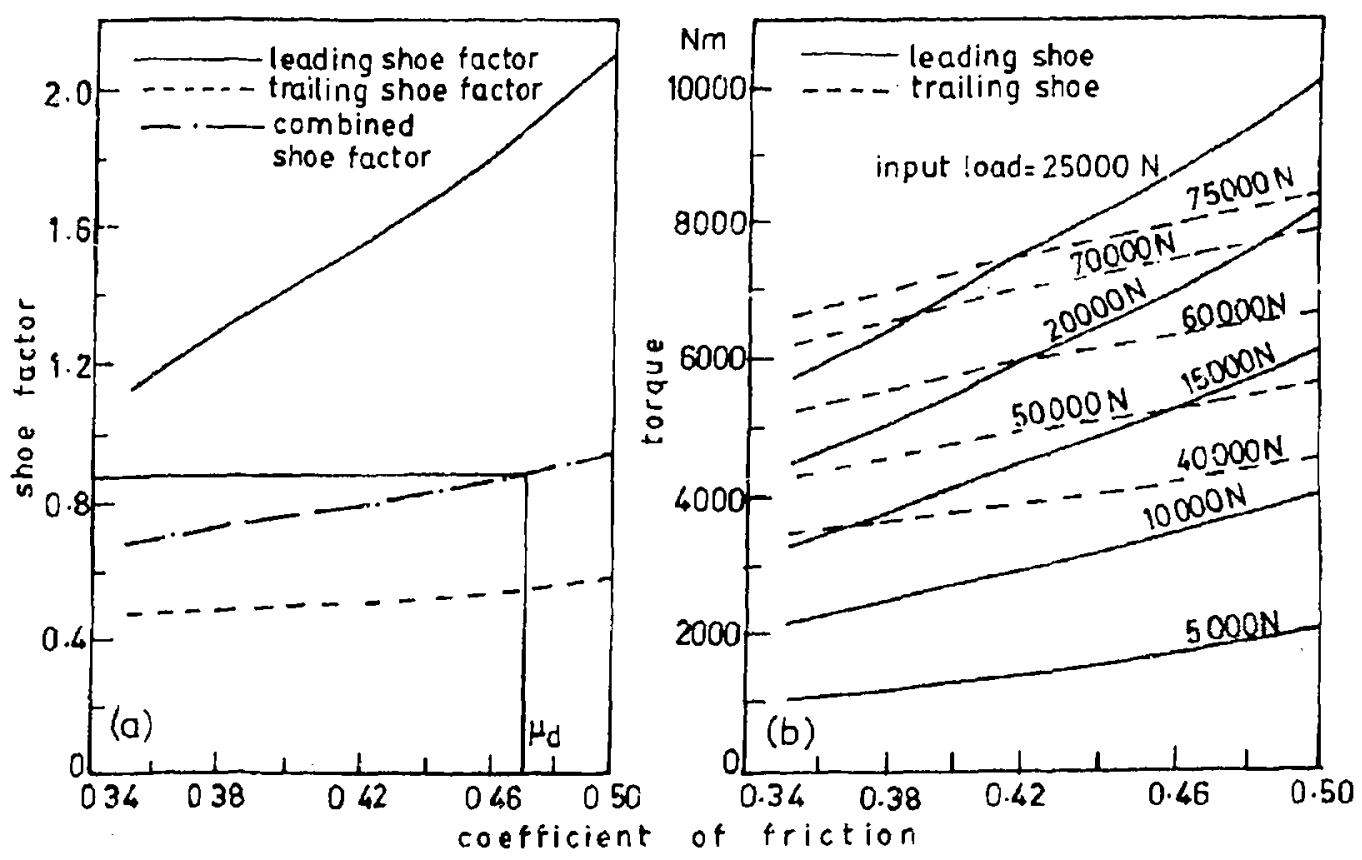

Figure 18. FEM analysis in ' $S$ ' cam brake shoe. (a) Variation of shoe factor with coefficient of triction. (b) Variation of brake torque with coefficient of friction for different input loads.

The coefficient of friction for the lining used in the experiment as measured by the Girling scale rig was 0.38 . Thus it can be concluded that the dynamic coefficient of friction of a particular grade of lining will be different from the value obtained from the Girling scale rig. The same grade of lining will have different dynamic coefficient of friction values in different sizes and types of brakes as conformability and loss of contact area are different.

The pressure distribution is shown in figure 20a for both static and dynamic cases
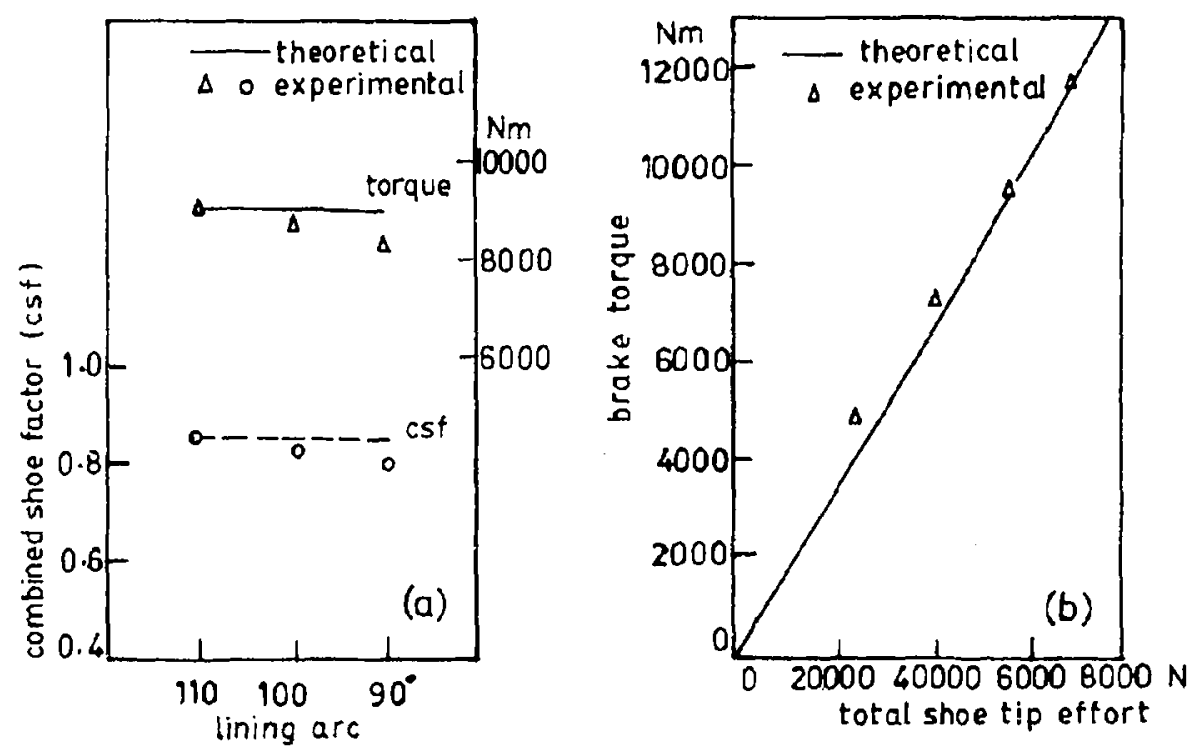

Figure 19. ' $S$ ' cam brake-experimental verification on dynamometer. (a) Variation of combined shoe factor and brake torque with lining arc. (b) Variation of brake torque with total shoe tip effort. 
Table 4. Torque/brake or brake factor variation with arc length of lining in ' $S$ ' cam brake.

\begin{tabular}{|c|c|c|c|c|c|c|}
\hline & \multicolumn{2}{|c|}{110} & \multicolumn{2}{|c|}{100} & \multicolumn{2}{|c|}{90} \\
\hline & $\begin{array}{l}\text { Theor- } \\
\text { etical }\end{array}$ & $\begin{array}{l}\text { Experi- } \\
\text { mental }\end{array}$ & $\begin{array}{l}\text { Theor- } \\
\text { etical }\end{array}$ & $\begin{array}{l}\text { Experi- } \\
\text { mental }\end{array}$ & $\begin{array}{l}\text { Theor- } \\
\text { etical }\end{array}$ & $\begin{array}{l}\text { Experi- } \\
\text { mental }\end{array}$ \\
\hline \multicolumn{7}{|l|}{ Shoe tip effort (N) } \\
\hline Leading & 11836 & & 12050 & & 12397 & \\
\hline Trailing & 40355 & & 40141 & & 39794 & \\
\hline Total & 52191 & 52191 & 52191 & 52191 & 52191 & 52191 \\
\hline Torque $(\mathrm{Nm})$ & 9285 & 9276 & 9224 & 8920 & 9143 & 8563 \\
\hline Shoe factor: Leading & 1.89 & & 1.84 & & 1.77 & \\
\hline Trailing & 0.55 & & 0.55 & & 0.55 & \\
\hline Combined shoe factor & 0.86 & 0.86 & 0.85 & 0.82 & 0.84 & $0 \cdot 79$ \\
\hline
\end{tabular}

Dynamic coefficient of friction (theoretical) $=0.47$

for the H2LS brake. The peak pressure at the abutment end increases as the arc length reduces. Even though the pressurc increases with the reduction in arc length, the brake torque reduces as the area over which the higher pressure arc decreases. Figure 20b, shows the pressure distribution over the arc length (for 100 degree arc) for various output deceleration levels. It can be seen that the pressure pattern is almost the same for different values of deceleration levels.

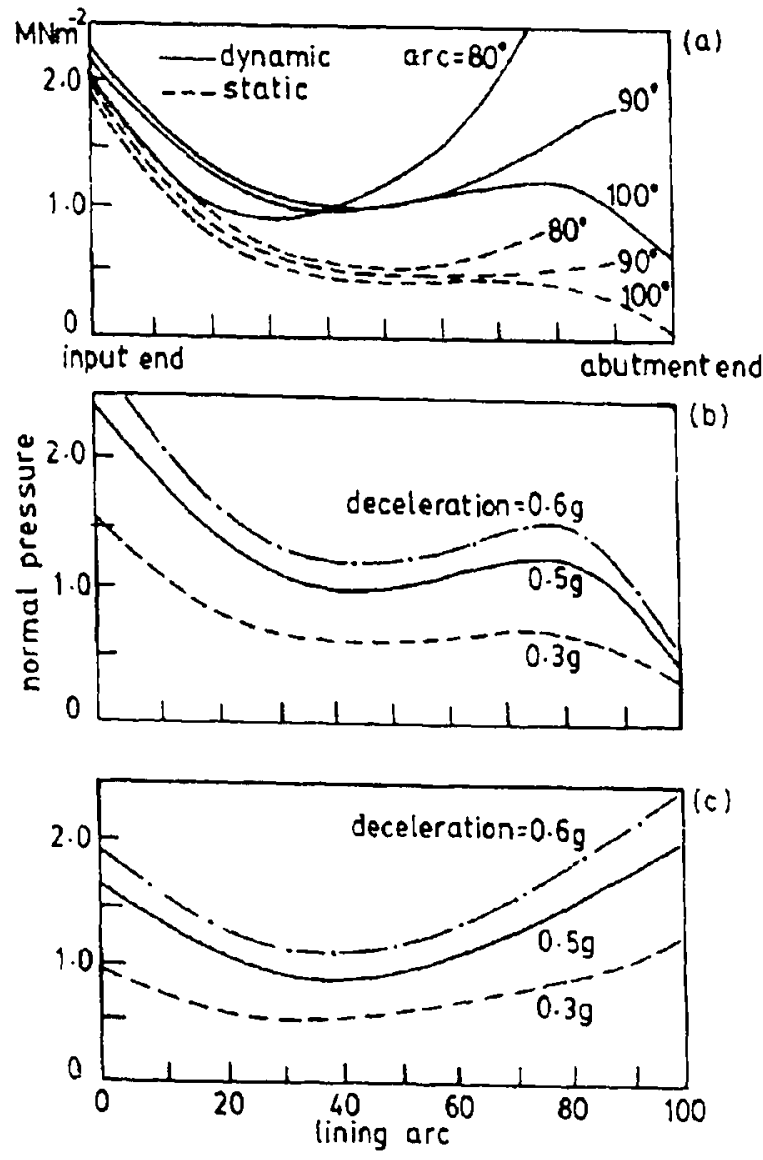

Figure 20. H2LS brake shoe-normal pressure distribution along the arcuate length. (a) Pressure distribution variation with lining arc lengths $-0.5 \mathrm{~g}$ deceleration. (b) Pressure distribution at different deceleration levels. (c) Lining moved towards input end by $10^{\circ}$. 
(a)

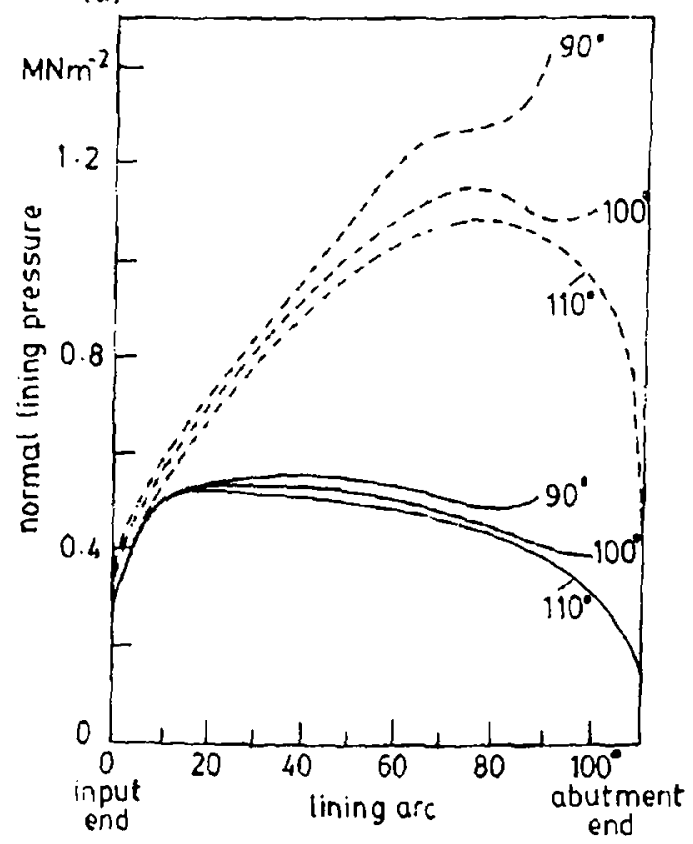

(b)

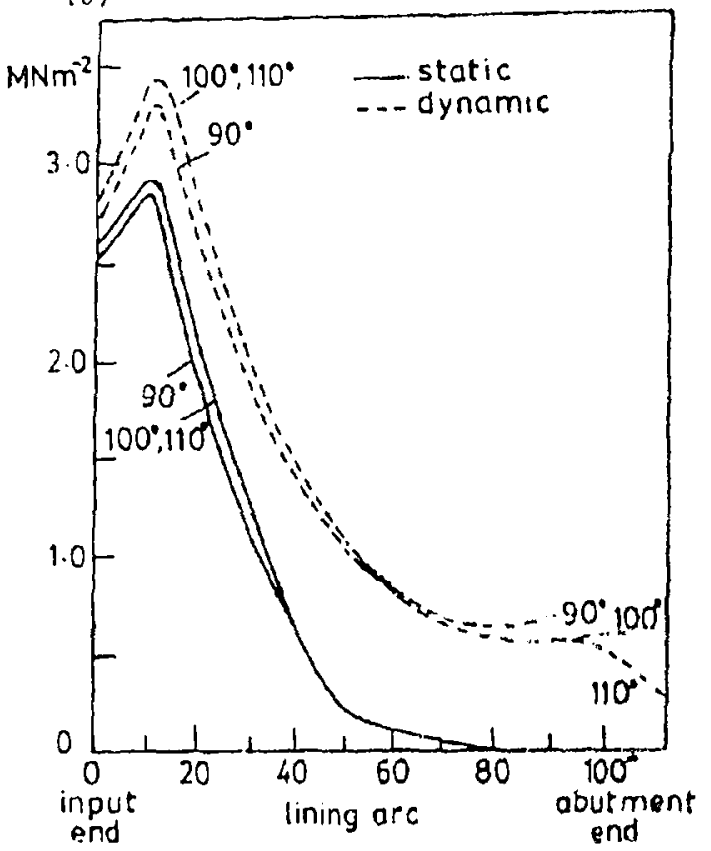

Figure 21. Pressure distribution along the lining arc-FEM analysis on ' $\$$ " cam brake shoe, for leading (a) and trailing (b) shoes.

When the brake lining (100 degree are) is moved towards the input end by an angle of $10^{\circ}$, the resulting pressure distribution is shown in figure $20 \mathrm{c}$. It can be observed that as the deceleration level increases, the pressure distribution pattern remains the same. The eflect of moving the brake lining by $10^{\prime \prime}$ results in the reduction of the maximum pressure.

Pressure distribution curves for the leading and trailing shoes of the ' $S$ ' cam brake are shown in figure 21. As in the case of H2LS brakes the pressures are higher for the dynamic case even in the case of ' $S$ ' cam brake shoes. However, for a dynamic situation, increases in the peak values are 2 to 3 times in case of the leading shoe whereas the absolute peak values in the case of the trailing shoe are much higher.

The stress contour plot of the H2LS shoe web is shown in figure 22. The maximum tensile stress value of $270 \mathrm{MN} / \mathrm{m}^{2}$ occurred near the input end where the crosssectional area is the least. The actual failures during the fatigue test on these brake shoes occur in the same area, thus conforming to theoretical predictions. Maximum compressive stress of around $313 \mathrm{MN} / \mathrm{m}^{2}$ occurred near the abutment area and these stresses are mainly contact stresses.

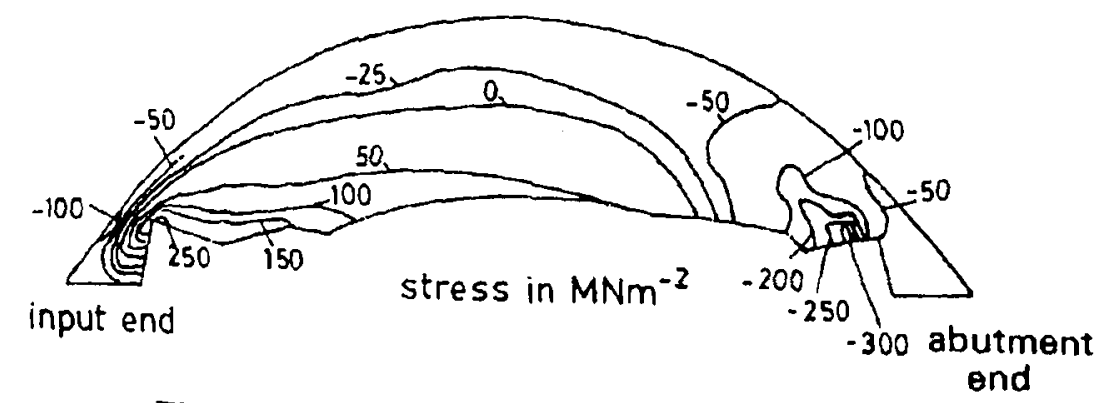

Figure 22. Stress plot on H2LS brake shoe web. 

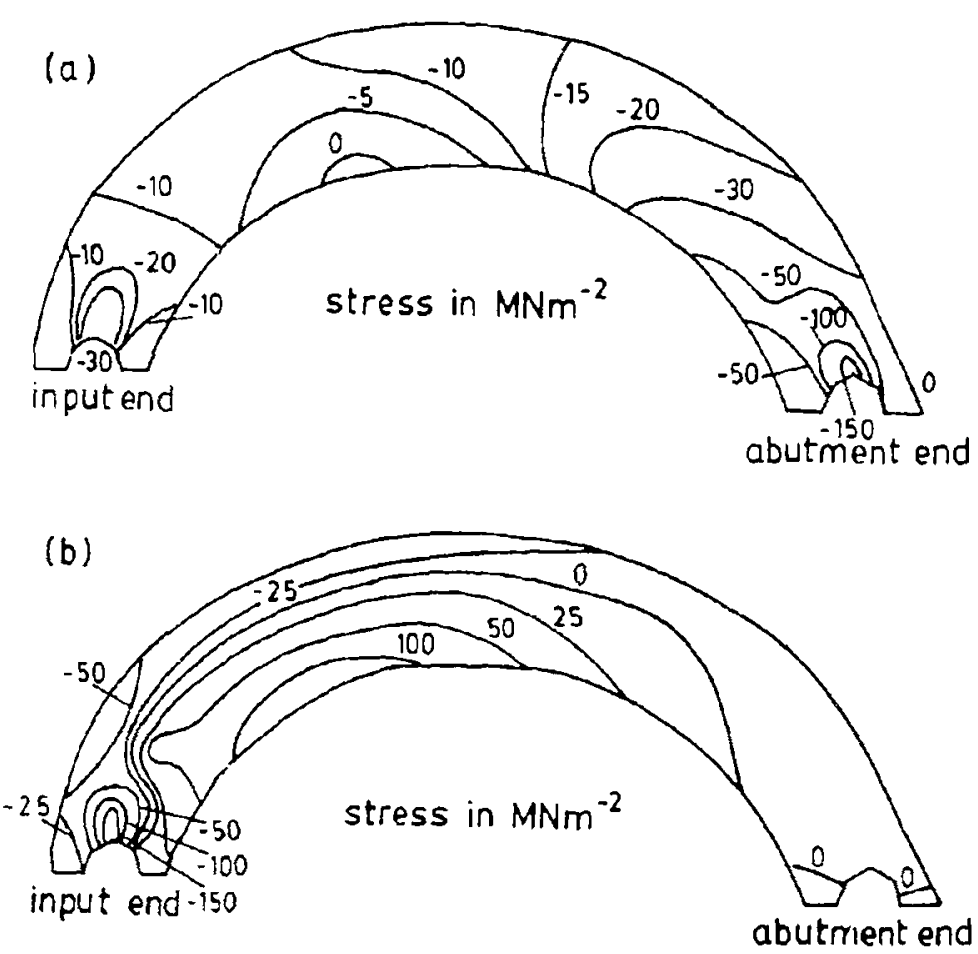

Figure 23. Stress plot on ' $S$ ' cam brake shoe web, for leading (a) and trailing (b) shoes.

The stress contour plot of the leading and the trailing shoe webs of the ' $S$ ' carn brake shoes are shown in figure 23 . The leading shoe web is subjected to compressive stresses only, the stress value being about $150 \mathrm{MN} / \mathrm{m}^{2}$ at the abutment end. In case of the trailing shoe, the bottom portion of the web is subjected to tensile stresses and the top portion to compressive stresses. The maximum tensile stress of $100 \mathrm{MN} / \mathrm{m}^{2}$ is at the input portion.

\section{Conclusions}

(1) The predicted temperatures at the end of braking during any fade and cooling cycle are in agreement with experimental data. The predictions of peak temperatures are, however, on the conservative side.

(2) The effect of heating under the influence of the brake shoe and the cooling in between the shoes have been accounted for in the analysis through a clock mechanism developed for this purpose.

(3) A dynamic friction coefficient concept was introduced. Usirg this concept, the brake torques were determined for various arc lengths and these agree well with experimental data.

(4) The highly stressed zones in the brake shoe web were identified from the analysis and these were found to be the actual failure zones observed in practice. 


\section{List of symbols}

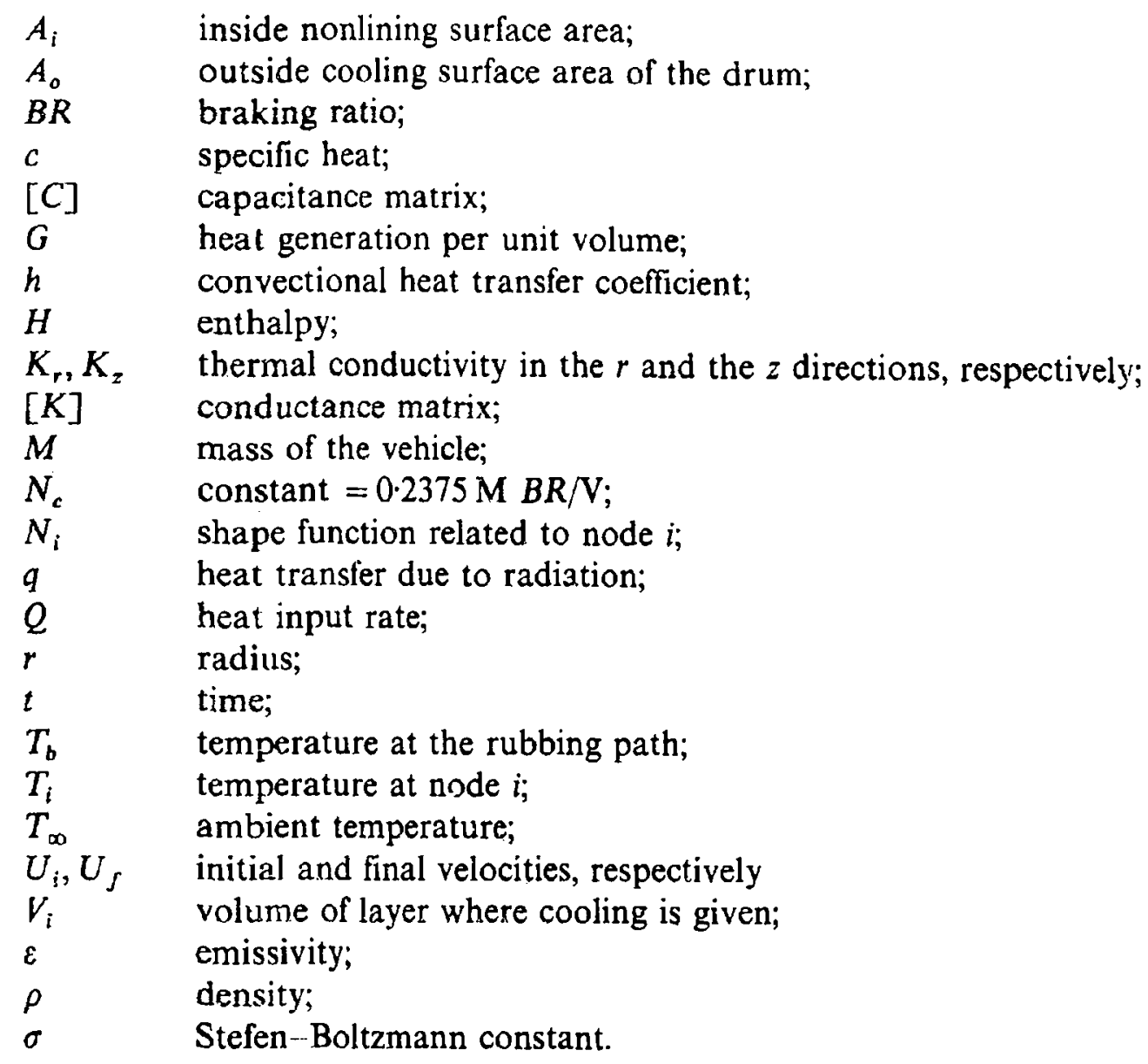

\section{References}

Ashworth F J, Sherbiny M E, Newcomb T P 1977 Proc. Inst. Mech. Eng. 191: 169-176

Comini G, Del S, Lewis R W, Zienkiwicz O C 1974 Finite element analysis of nonlinear heat conduction including phase change. Int. J. Numer. Meth. Eng. 8: 613-624

Fazekas G A G 1953 Temperature gradients and heat stresses in brake drums. Trans. Soc. Automobile Eng. NY 61: 279-308

Highley F H 1971 Techniques for determining the thermal characteristics of brake drums and discs. SAE paper 710589 , pp. $2020-2028$

Morgan K, Lewis R W, Seetharamu K N 1981 Modelling heat flow and thermal stresses in ingot casting. Simulation 36: 55-63

Newcomb T P 1958-59 Transient temperatures in brake drum and linings. Proc. Inst. Mech. Eng. 7: (a) 224-227, (b) 227-284

Newcomb T P 1963 Friction surface area required in brakes. Engineering 195: 28

Ramachandra Rao V T V S 1988 Analytical and experimental investigation on drum and disc brakes. Ph D thesis. Indian Institute of Technology, Madras

Ramachandra Rao V T V S, Ramasubramanian H, Seetharamu K N 1985 Simulation of temperature distribution in drum brake - comparison by measurements. Proc. NUMETA' 85 Conference, Swansea, pp. 841-845

Ramachandra Rao V T V S, Subramani D A 1993 Pressure distribution in disc brakes between rotor and pads. (communicated)

Sisson A E 1978 Thermal analysis of vented brake rotors. SAE paper 780352, pp. 1685-1694 